\title{
Reply to cardiothoracic transplants in India-why adequate immunogenetic workup for potential recipients is a must
}

\author{
Sunil Shroff ${ }^{1} \cdot$ Kriti Mittal $^{1} \cdot$ Sumana Navin ${ }^{1}$ \\ Published online: 15 October 2020 \\ (C) Indian Association of Cardiovascular-Thoracic Surgeons 2020
}

Thank you for your comments on our article [1]. While we appreciate that there is requirement to evolve the heart transplant program with evidence that relates to immunological workup and the outcome, I wish to point out that the Indian program is still in early stages of development and is still growing. Most of the solid organ transplant program's development has taken place with the growth of the kidney transplant program. Even with the deceased donor kidney transplants, we still have not been able to offer human leucocyte antigen (HLA)matched kidneys and many centres continue to use complement-dependent cytotoxicity (CDC) crossmatch.

The logistic challenges to upgrade the immunological workup include trained manpower, investment in a centralised lab services and regional cooperation, transportation and finding investment from sustainability perspective. Health in India is a state subject (https://en.wikipedia.org/wiki/Healthcare_in India) and it has 28 states and 9 union territories, of these only 13 states do deceased donations. Hence, a state has to take a call regarding establishing regional centralised immunological lab services for storage of sera and HLA profile of recipients and cross match and HLA profiling of deceased donor at the time of transplants. Occasionally hearts have travelled on flights for over $3 \mathrm{~h}$ from regions that have no transplant or lab services and then ischaemia time becomes an issue. Currently India's gross domestic product (GDP) expenditure on health too is low at less than $4 \%$, of which only $1 \%$ comes from the government and the rest from private sector (https://data.worldbank.org/indicator/SH.XPD.GHED.GD. ZS). Again, one lab may not be sufficient because some states are larger in both area and population than countries like England or Germany. The other challenge is that most of

Sunil Shroff

shroff@mohanfoundation.org

1 MOHAN Foundation, 267 Kilpauk Garden Road, Chennai 600010, India these transplants happen in private sector hospitals and very little happens in government public sector hospitals, where the services are more basic.

The overall purpose of the article was to capture the twenty-five years of the growth of the heart transplant program in India after passing of the law on brain death and make a few essential recommendations for the program to grow and not to discuss any of the finer points or make recommendations. However, we do appreciate the inputs from the author.

We wish to add that as the number of overall deceased donor transplants increase, adding the immunological workup will fall into place and at least in the state of Tamil Nadu, which has been the leader in the organ transplant program, including heart and lung transplants, a proposal has already been submitted to the government for centralised immunology lab services a few years back (https://www.thehindu.com/news/cities/chennai/ immunology-lab-for-state/article7717515.ece). The state of Karnataka too is considering similar proposals.

\section{Compliance with ethical standards}

Conflict of interest Nil

\section{Reference}

1. Shroff S, Mittal K, Navin S. Heart transplantation in India-looking back as we celebrate 25 years of the transplant law. Indian J Thorac Cardiovasc Surg. 2020. https://doi.org/10.1007/s12055-020-00957-6.

Publisher's note Springer Nature remains neutral with regard to jurisdictional claims in published maps and institutional affiliations. 